\title{
Expression of TIPE family members in human colorectal cancer
}

\author{
MENGYA ZHONG ${ }^{1 *}$, ZHIJIAN CHEN $^{1 *}$, YANG YAN $^{1 *}$, ARGEN·BAHET $^{1}$, \\ XIN CAI $^{1}$, HUIYU CHEN ${ }^{1}$, HONGGANG RAN ${ }^{1}$, KAIYONG QU $^{1}$, ZHAOPU HAN ${ }^{1}$, \\ GUOHONG ZHUANG ${ }^{1}$, SHIFENG ZHANG ${ }^{2-4}$ and YINAN WANG ${ }^{5}$ \\ ${ }^{1}$ Cancer Research Center, School of Medicine, Xiamen University, Xiamen, Fujian 361005; ${ }^{2}$ Department of Gastrointestinal \\ Surgery, Zhongshan Hospital of Xiamen University; ${ }^{3}$ Institute of Gastrointestinal Oncology, Zhongshan Hospital of \\ Xiamen University; ${ }^{4}$ Xiamen Municipal Key Laboratory of Gastrointestinal Oncology, Xiamen, Fujian 361004; \\ ${ }^{5}$ Department of Basic Medical Science, School of Medicine, Xiamen University, Xiamen, Fujian 361005, P.R. China
}

Received January 15, 2020; Accepted November 12, 2020

DOI: $10.3892 / 01.2020 .12379$

\begin{abstract}
The tumor necrosis factor $\alpha$-induced protein 8 (TNFAIP8)-like (TIPE) protein family comprises four members, namely TNFAIP8, TIPE1, TIPE2 and TIPE3, which are involved in multiple processes in cancer. The current study aimed to investigate the expression patterns and potential clinical roles of the TIPE family members in human colorectal cancer (CRC). Paired tumor and adjacent tissue samples were collected from 49 patients with CRC, and the relative mRNA expression levels of the TIPE family members in these samples were evaluated by using reverse transcription-quantitative PCR, and the protein levels in five randomly selected pairs of tumor and adjacent tissue samples were detected by western blot analysis. The mRNA expression levels of the TIPE family members were significantly downregulated in CRC tumor tissues compared with those in the adjacent tissues; however, within each sample, TNFAIP8 and TIPE3 protein levels were only partially consistent with their mRNA levels. In addition, the mRNA expression levels between each pair of TIPE family members exhibited a positive linear relationship, and TIPE2 mRNA levels exhibited strong linear associations with those of TNFAIP8 and TIPE1. TNFAIP8 mRNA expression levels
\end{abstract}

Correspondence to: Dr Shifeng Zhang, Department of Gastrointestinal Surgery, Zhongshan Hospital of Xiamen University, 201-209 Hubin South Road, Xiamen, Fujian 361004, P.R. China E-mail:cnfj@xmu.edu.cn

Dr Yinan Wang, Department of Basic Medical Science, School of Medicine, Xiamen University, 422 Siming Nan Road, Xiamen, Fujian 361005, P.R. China

E-mail: yinanwang@xmu.edu.cn

${ }^{*}$ Contributed equally

Key words: tumor necrosis factor $\alpha$-induced protein 8 , tumor necrosis factor $\alpha$-induced protein 8 -like 1, tumor necrosis factor $\alpha$-induced protein 8 -like 2 , tumor necrosis factor $\alpha$-induced protein 8-like 3, colorectal cancer in tumor tissues were significantly associated with the tumor differentiation grade, and TIPE2 mRNA expression levels in tumor tissues were significantly associated with sex. TIPE1 and TIPE3 mRNA expression levels in tumor tissues exhibited no associations with patient clinicopathological characteristics. In addition, the mRNA expression patterns of the TIPE family members were analyzed using data from The Cancer Genome Atlas data set, and the results also demonstrated that TNFAIP8, TIPE2 and TIPE3 mRNA levels were downregulated in patients with colon adenocarcinoma compared with those in normal controls. These results provided evidence that the four members of the TIPE family may affect each other to mediate the carcinogenesis of CRC, and that TIPE2 may serve an important role in CRC.

\section{Introduction}

According to the new case data for cancer of Globocan 2018 (http://gco.iarc.fr.), combined with the statistics of patients in America with tumors among male and female in 2020, colorectal cancer (CRC) has become the third most common cancer in the world, and the incidence of CRC is expected to increase (1-3). Data from Globocan reports that compared with 2018 by 2040 , the incidence of colon cancer will increase 1.75 times, while rectal cancer will increase 1.67 times (https://gco.iarc.fr/tomorrow/home). A number of potential molecular targets or markers for CRC have been identified by The Cancer Genome Atlas (TCGA) project, including tumor necrosis factor $\alpha$-induced protein 8 (TNFAIP8) $(2,4)$. This protein belongs to the TNFAIP8-like (TIPE) family, which contains three other members, TIPE1, TIPE2 and TIPE3 $(5,6)$. Although the members of the TIPE family have similar amino acid sequences, they are involved in different biological activities $(6,7)$.

TNFAIP8 was the first protein of this family to be discovered, and its expression is limited in various normal tissues, but upregulated in malignant cells of various cancers, such as chronic myelogenous leukemia, lymphoblastic leukemia, and lung carcinoma (8-10). Previous studies have suggested an association between high levels of TNFAIP8 expression and tumorigenesis $(5,11,12)$. TNFAIP8 has several variants and 
different protein isoforms that coexist in the same cells (https://www.ncbi.nlm.nih.gov/gene/25816, accessed on 23 December 2019). Recent studies have demonstrated that in certain TCGA data sets, TNFAIP8 variant 2 (v2) mRNA (encoding isoform b) is upregulated in eight types of human cancer, but no changes have been identified in colon adenocarcinoma; TNFAIP8 v1 mRNA is downregulated in seven types of human cancer, including colon adenocarcinoma; additionally, low levels of TNFAIP8 v3-v6 mRNA are expressed in both cancer or normal tissue $(4,12)$. A previous study has suggested that the TNFAIP8 protein that is upregulated in cancer is encoded by TNFAIP8 v2 mRNA, and that TNFAIP8 v2 promotes carcinogenesis by suppressing p53 activity in human cancer cells (4). The functions of TNFAIP8 in promoting cell proliferation and inhibiting apoptosis are considered to facilitate its cancer-promoting role $(13,14)$.

In contrast to TNFAIP8 expression, TIPE1 expression is low in certain types of cancer, including hepatocellular carcinoma (HCC), gastric and lung cancer, and CRC (15-18). However, high expression levels of TIPE1 are detected in most human carcinoma cell lines, including cervical and ovarian cancer cell lines $(5,19)$. Different posttranslational modifications of TIPE1 have also been predicted to exist $(12,20)$. TIPE1 has two transcript variants, both of which encode the same protein (https://www.ncbi.nlm.nih.gov/gene/126282, accessed on 23 December 2019). TIPE1 inhibits the p65 and c-Jun $\mathrm{N}$-terminal kinase pathways by suppressing Racl activity to increase caspase-mediated apoptosis in HCC cells (15). In gastric cancer, TIPE1 suppresses cell invasion and migration by inhibiting the $\mathrm{Wnt} / \beta$-catenin signaling pathway (18). TIPE1 is regarded as a proapoptotic factor with the ability to suppress cell migration $(15,18)$.

Unlike other TIPE family members, TIPE2 has no transcript variants (https://www.ncbi.nlm.nih.gov/gene/79626). TIPE2 has been reported to be expressed at lower levels in certain types of cancer, such as breast and gastric cancer, HCC and lung cancer, compared with those in adjacent normal tissues (21-24). TIPE2 negatively regulates Toll-like and T cell receptors to avoid excessive immune response and maintain immune homeostasis (7). In addition, TIPE2 is an inhibitor of the NF- $\kappa \mathrm{B}$ and MAPK signaling pathways and helps reduce the activation of activator protein-1 and NF- $\kappa \mathrm{B}(25,26)$. TIPE2 is a negative regulator of immunity and inflammation that can promote apoptosis and inhibit cell migration $(7,24)$.

TIPE3 specifically binds the second messenger of phospholipids and promotes cell proliferation, and the expression of TIPE3 is upregulated in lung, esophageal and cervical cancer, as well as colon adenocarcinoma (27). TIPE3 has two transcript variants (v1 and v2) that encode two isoforms, and isoform 2 has a shorter N-terminus compared with that of isoform 1 (https://www.ncbi.nlm.nih.gov/gene/388121, accessed on 21 December 2019). TIPE3 mRNA v1 and protein are highly expressed in glioblastoma (GBM), where its protein expression is negatively associated with p38 phosphorylation and apoptosis, and only TIPE3 isoform 1 interacts with p38 (28). TIPE3 is upregulated in lung cancer compared with adjacent non-tumor tissues, and different subcellular localization of TIPE3 induces different effects; TIPE3 was highly expressed in plasma membrane of the lung cancer cells with long pseudopodia, particularly in the position of protrusion, indicating that it was involved in cell motility and contributed to the growth and migration of lung cancer cells (29). However, in the cytoplasm, both isoform 1 and 2 of exogenous TIPE3 can attenuate the proliferation and migration of lung cancer cells by inhibiting AKT and ERK activation (29). Another study has demonstrated that the mRNA expression of TIPE3 is downregulated in certain types of human cancer, such as nasopharyngeal carcinoma (NPC), bladder, head and neck, lung and prostate cancer, as well as CRC, and is associated with DNA CpG island hypermethylation; in addition, TIPE3 inhibits NPC cell proliferation, migration and invasion (30). Therefore, the biological role of TIPE3 remains unknown, and only a limited number of studies have demonstrated that TIPE3 is a carcinogen $(28,29)$.

In previous studies, TNFAIP8, TIPE2 and TIPE3 levels have been reported to be higher in CRC compared with those in adjacent non-tumor tissues $(5,6)$. In addition, TIPE1 is expressed at lower levels in CRC compared with those in adjacent non-tumor tissues. However, there are limited reports on the transcription levels of the TIPE family members in CRC, and it is unclear whether the expression levels of TIPE family genes within each sample are interrelated. The present study aimed to further explore the co-expression patterns of the TIPE family members within individual CRC samples and to assess the possible associations between the mRNA expression levels of the TIPE family members and the clinicopathological characteristics of patients with CRC.

\section{Materials and methods}

Tissue samples. Tumor and paired adjacent tissues from 49 patients with colorectal adenocarcinoma who had not received radiotherapy and chemotherapy prior to the surgery were collected from Zhongshan Hospital affiliated with Xiamen University (Xiamen, China) from January 2017 to December 2018. The age range was 34 to 87 years old, with an average age of 60 years old. Among them, there were 35 males and 14 females. The clinical specimens were histologically confirmed in the pathology department. Besides, there were 4 clinical cases without differentiation related information. The adjacent tissues were collected $3-5 \mathrm{~cm}$ away from the tumor edge; they may have included adenoma tissue adjacent to the carcinoma rather than heterogeneous samples composed of mucosa, muscularis and serosa. The samples were frozen and stored at $-80^{\circ} \mathrm{C}$ until further analysis. All samples were obtained with patient written consent and approval of the Committee on Medical Ethics of Zhongshan Hospital affiliated with Xiamen University. For western blot analysis, regardless of clinicopathological characteristics such as age, sex, tumor size and metastasis, five samples were randomly selected from the patients.

RNA isolation and reverse transcription. Total RNA was extracted from paired tumor and normal tissues from 49 patients with CRC using TransZol Up reagent (TransGen Biotech Co., Ltd.) according to the manufacturer's instructions. The RNA concentration was determined using a Pultton P100 Micro Volume Spectrophotometer (Pultton Technology, Ltd.). Every $1 \mu \mathrm{g}$ of the total RNA was reverse-transcribed into cDNA in a $20 \mu \mathrm{l}$ system of TransScript ${ }^{\circledR}$ All-in-One 
First-Strand cDNA Synthesis SuperMix for qPCR (One-Step gDNA Removal) (TransGen Biotech Co., Ltd.) according to the manufacturer's instructions.

Reverse transcription-quantitative PCR (RT-qPCR). The expression levels of TNFAIP8, TIPE1, TIPE2 and TIPE3 mRNA were evaluated by RT-qPCR using $\beta$-actin as the internal control. The generated cDNAs were used for qPCR using TransStart Top Green qPCR SuperMix (TransGen Biotech Co., Ltd.) according to the manufacturer's protocol. The qPCR process was performed using a two-step method in a $20-\mu 1$ total reaction volume using a CFX Connect ${ }^{\mathrm{TM}}$ Real-Time system (Bio-Rad Laboratories, Inc.). The following thermocycling conditions were used: $94^{\circ} \mathrm{C}$ for $30 \mathrm{sec}$, followed by 40 cycles of $94^{\circ} \mathrm{C}$ for $5 \mathrm{sec}, 60^{\circ} \mathrm{C}$ for $15 \mathrm{sec}$, and $72^{\circ} \mathrm{C}$ for $10 \mathrm{sec}$ followed by final extension at $72^{\circ} \mathrm{C}$ for $40 \mathrm{sec}$. The primer sequences were as follows: TNFAIP8 forward, 5'-ATGCAC TCCGAAGCAGAAGAATCC-3' and reverse, 5'-CGTCTA TTAAGGTGGTGGCGATGG-3'; TIPE1 forward, 5'-GGA CACCTTCAGCACCAAGAGC-3' and reverse, 5'-GTGGCG CGGTACAGCTCATC-3'; TIPE2 forward, 5'-ATGTGCTGC TAGAGTTGGTGGAAC-3' and reverse, 5'-TTGCCAAGG TGCTGAGTGAAGTC-3'; TIPE3 forward, 5'-GAACCAGAC CGCCATGACCATTG-3' and reverse, 5'-CCAGTTCATGCA CCAGGTCCTTG-3'; and $\beta$-actin forward, 5'-AGCGAGCAT CCCCCAAAGTT-3' and reverse, 5'-GGGCACGAAGGC TCATCATT-3'. The relative mRNA expression of the target gene in each sample was calculated using the quantification cycle $(\mathrm{Cq})$ value based on the $2^{-\Delta \Delta \mathrm{Cq}}$ method, where $\Delta \mathrm{Cq}=\mathrm{Cq}$ (target)-Cq (control) (31).

Western blot analysis. The tissue samples were lysed using RIPA buffer (Sigma-Aldrich; Merck KGaA) with $1 \%$ protease inhibitor cocktail and $1 \%$ phenylmethanesulfonyl fluoride (Gold Biotechnology, Inc.) at $4^{\circ} \mathrm{C}$ and cleared by centrifugation for $10 \mathrm{~min}$ at $10,000 \mathrm{x} \mathrm{g}$ at $4^{\circ} \mathrm{C}$. The protein concentration was determined by the Bradford assay (Bio-Rad Laboratories, Inc.). The protein samples were separated by $12 \%$ or $15 \%$ SDS-PAGE and transferred to polyvinylidene difluoride membranes (EMD Millipore). The membranes were blocked by $5 \%$ skimmed milk at room temperature for $1 \mathrm{~h}$ and incubated with the following specific primary antibodies at $4{ }^{\circ} \mathrm{C}$ overnight: Rabbit polyclonal antibodies against TNFAIP8 (1:500; cat. no. ab195810; Abcam), TIPE1 (1:1,000; cat. no. SAB2102488; Sigma-Aldrich; Merck KGaA), TIPE2 (1:500; cat. no. 15940-1-AP; ProteinTech Group, Inc.) and TIPE3 (1:1,000; cat. no. AP11822c; Abgent, Inc.), and a rabbit monoclonal antibody against $\beta$-actin $(1: 5,000$; cat. no. AB0035; Abways Technology, Inc.). Subsequently, the membranes were washed by TBST which contained $0.05 \%$ Tween 20 (cat. no. T1085; Solarbio, Inc.), and incubated with a horseradish peroxidase-conjugated goat anti-rabbit IgG antibody (1:2,000; ZF-0311; OriGene Technologies, Inc.) for $1 \mathrm{~h}$ at room temperature. The protein bands were visualized using enhanced chemiluminescence reagents (cat. no. P10300; NCM Biotech). The grayscale values of the protein band images were analyzed using ImageJ software (v.1.51; National Institutes of Health), and the relative protein expression levels were calculated as the ratio of the grayscale value of the protein band to that of the $\beta$-actin band.
TCGA gene expression analysis. TIPE family mRNA data from normal colon and CRC samples in TCGA were analyzed by using the UALCAN web server (http://ualcan.path.uab. edu/) (32). Since the UALCAN Web server was produced using data from the TCGA, its analysis results are equivalent to the data provided by TCGA (32), so the expression and correlation analyses were performed on 243 adenocarcinoma, 37 mucinous adenocarcinoma and 41 normal samples from TCGA (32).

Statistical analysis. All statistical analyses were performed using GraphPad Prism 8.0 (GraphPad Software, USA). Each experiment was repeated at least 3 times and data were expressed as the means \pm standard error of mean (SEM). A paired Student's t-test was performed to examine the differences in relative mRNA expression levels of the target genes between CRC and paired adjacent tissues. For multiple comparisons, one-way ANOVA followed by the post hoc Bonferroni correction was used to adjust the significance levels and the corrected P-value was 0.0166. The associations between the expression levels of TIPE family members and the clinicopathological features of patients with CRC, including age, sex, tumor location, Tumor-Node-Metastasis (TNM) stage defined using the 8th Edition for TNM Classification of Malignant Tumors (33), degree of differentiation and lymph node metastasis, were analyzed by the $\chi^{2}$ test (all data satisfied the conditions of the $\chi^{2}$ test, and there was no need to use Fisher's exact test). The patients were divided into two groups (high or low expression) using the median mRNA expression value as the cut-off point. Linear regression analysis was performed to determine whether significant linear relationships existed among the TIPE family members. $\mathrm{P}<0.05$ was considered to indicate a statistically significant difference.

\section{Results}

TIPE family member mRNA expression in CRC. RT-qPCR analysis was performed to determine the relative mRNA levels of TIPE family members in the paired tumor and adjacent tissues from patients with CRC. The expression levels of TNFAIP8, TIPE1, TIPE2 and TIPE3 were significantly lower in the tumor tissues compared with those in the adjacent tissues (all P<0.0001; Fig. 1A-D). The RT-qPCR results demonstrated that the mRNA expression levels of TNFAIP8, TIPE1, TIPE2 and TIPE3 in the adjacent tissues were $2.8-, 2.4-, 2.5-$ and 3.9-fold higher, respectively, compared with those in the tumor tissues (Fig. 1A-D). The most notable fold-change was observed in the expression levels of TIPE3.

TIPE family protein expression in CRC. It has been reported that the protein expression levels of TNFAIP8, TIPE2 and TIPE3 are usually higher, and the protein expression of TIPE1 is lower in CRC tissues compared with those in adjacent or normal tissues $(16,27,34,35)$. To verify the protein expression levels of the TIPE family members, western blot analyses was performed using protein extracts from five randomly selected pairs of cancer and adjacent tissue samples. The results demonstrated that the protein and mRNA expression patterns of TIPE1 and TIPE2 were consistent in the five pairs of tissues, and the expression levels of these two proteins were appeared 
A

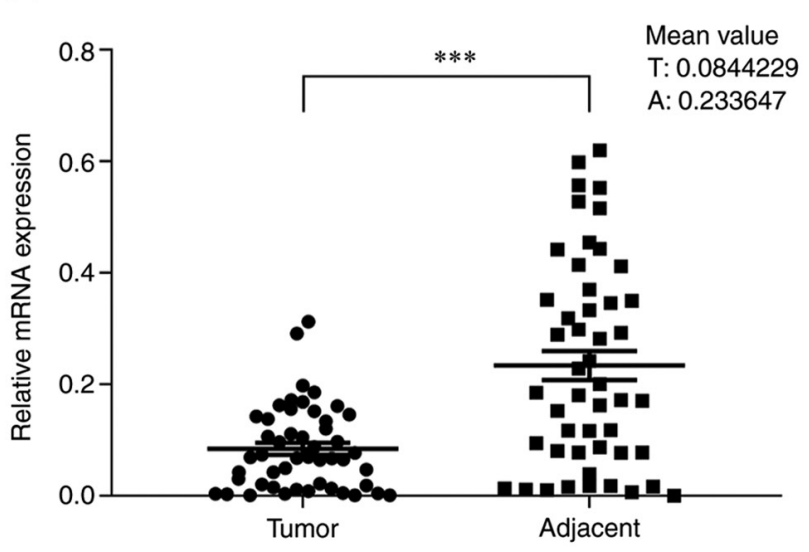

C

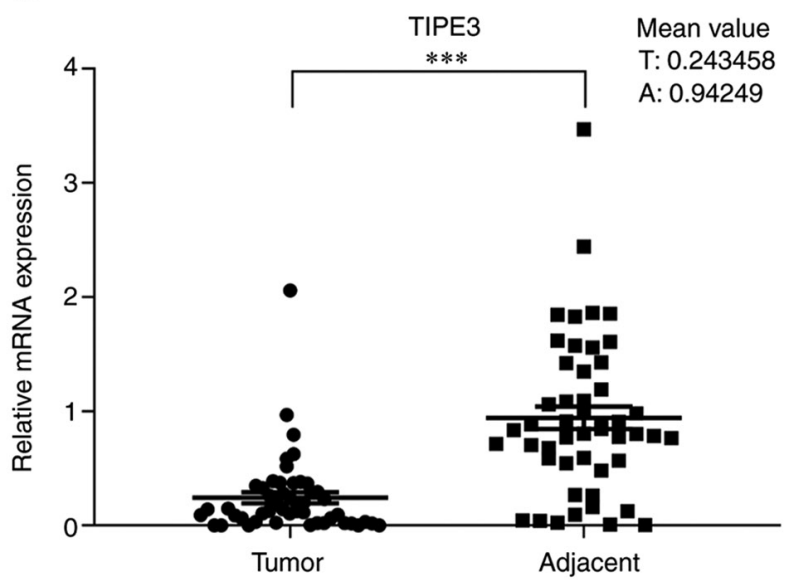

B TIPE1

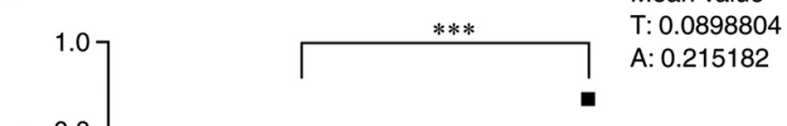

$E$

2

3
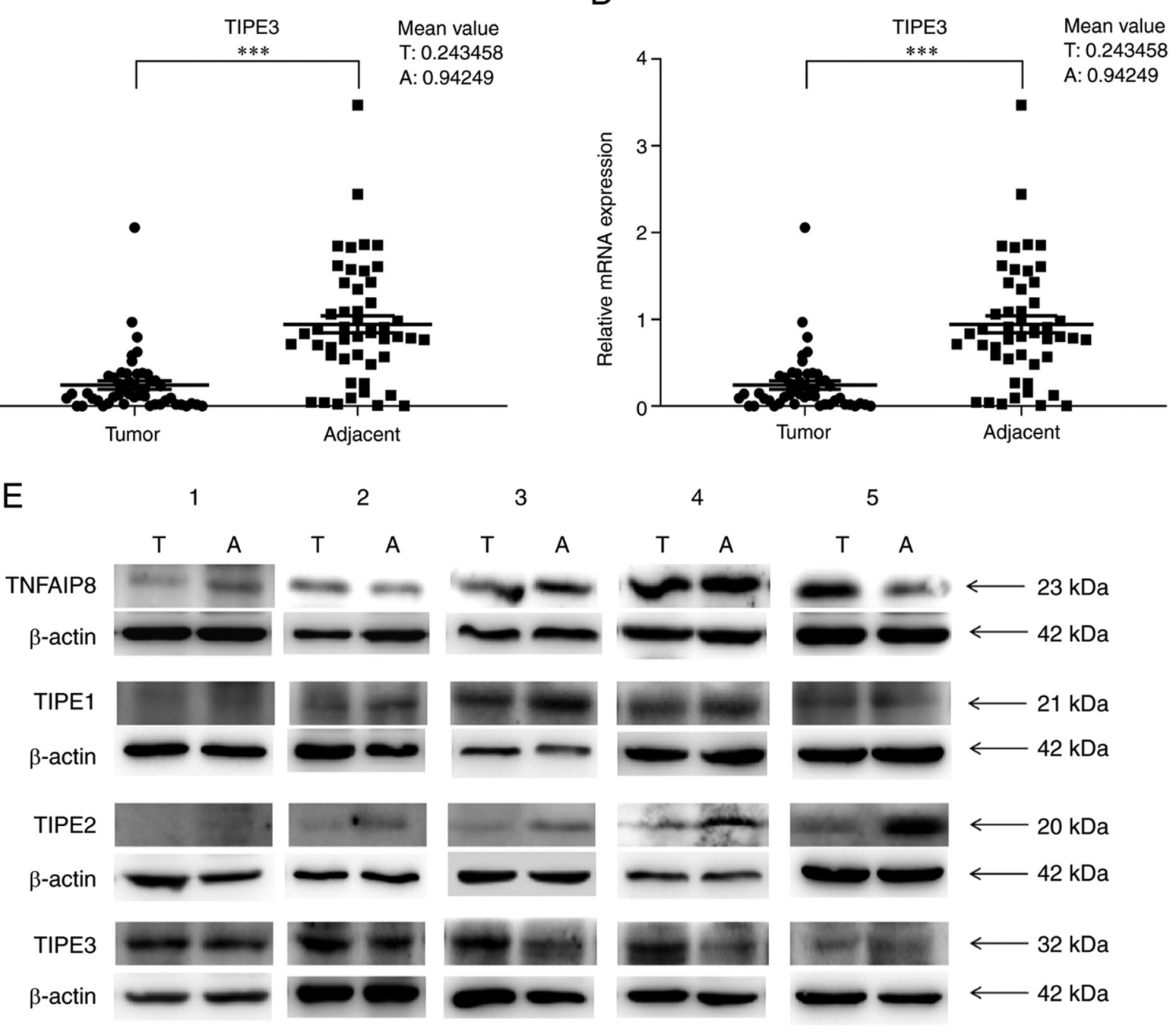

5

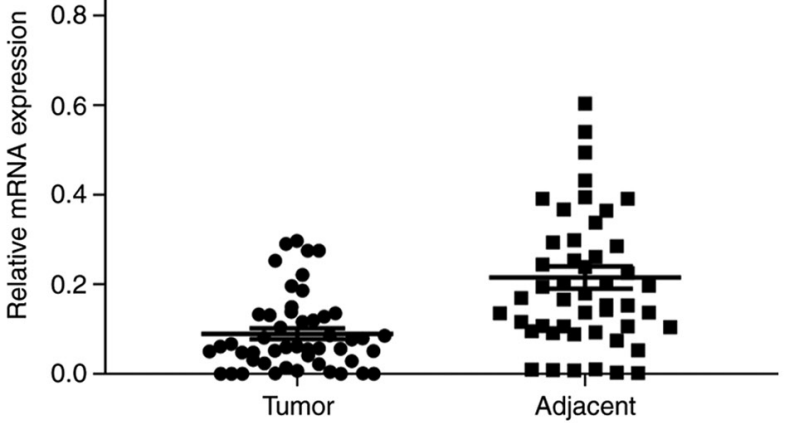

Adjacent

D 
Table I. Analysis of the association between TNFAIP8 expression and patient clinicopathological characteristics.

\begin{tabular}{|c|c|c|c|c|c|}
\hline \multirow[b]{2}{*}{ Variable } & \multirow[b]{2}{*}{$\mathrm{n}$} & \multicolumn{2}{|c|}{ TNFAIP8 expression } & \multirow[b]{2}{*}{$\chi^{2}$} & \multirow[b]{2}{*}{ P-value } \\
\hline & & High, n (\%) & Low, n (\%) & & \\
\hline \multicolumn{6}{|l|}{ Sex } \\
\hline Male & 35 & $20(80.0)$ & $15(62.5)$ & 1.838 & 0.1752 \\
\hline Female & 14 & $5(20.0)$ & $9(37.5)$ & & \\
\hline \multicolumn{6}{|l|}{ Age } \\
\hline$\geq 60$ & 35 & $20(80.0)$ & $15(62.5)$ & 1.838 & 0.1752 \\
\hline$<60$ & 14 & $5(20.0)$ & $9(37.5)$ & & \\
\hline \multicolumn{6}{|l|}{ TNM stage } \\
\hline I-II & 30 & $15(60.0)$ & $15(62.5)$ & 0.032 & 0.8575 \\
\hline III-IV & 19 & $10(40.0)$ & $9(37.5)$ & & \\
\hline \multicolumn{6}{|c|}{ Lymph node metastasis } \\
\hline Positive & 19 & $10(40.0)$ & $9(37.5)$ & 0.03224 & 0.8575 \\
\hline Negative & 30 & $15(60.0)$ & $15(62.5)$ & & \\
\hline \multicolumn{6}{|l|}{ Location } \\
\hline Colon & 32 & $17(68.0)$ & $15(62.5)$ & 0.1635 & 0.6860 \\
\hline Rectum & 17 & $8(32.0)$ & $9(37.5)$ & & \\
\hline \multicolumn{6}{|l|}{ Differentiation grade } \\
\hline Low & 5 & $5(21.7)$ & $0(0.0)$ & 5.38 & $0.0204^{\mathrm{a}}$ \\
\hline Medium and high & 40 & $18(78.3)$ & $22(100.0)$ & & \\
\hline
\end{tabular}

${ }^{\mathrm{a}} \mathrm{P}<0.05$. TNM, Tumor-Node-Metastasis; TNFAIP8, tumor necrosis factor $\alpha$-induced protein 8 . Note: The total number of cases was 49 , however, there were 4 clinical cases without differentiation related information.

those in the corresponding adjacent tissues (Fig. 1E; Table SI). In addition, the expression levels of TIPE3 in four cancer tissue samples were higher compared with those in the corresponding adjacent tissues, whereas the mRNA expression pattern exhibited the opposite trend (Fig. 1E; Table SI).

Association between TIPE family expression and patient clinicopathological characteristics. The associations between TIPE family member expression levels and the clinicopathological features of patients with CRC were analyzed. As presented in Tables I and II, the levels of TNFAIP8 mRNA in tumor tissues exhibited a significant association with the tumor differentiation grade $(\mathrm{P}=0.0204$, Table I), and the levels of TIPE2 mRNA in the tumor tissues were weakly associated with sex $(\mathrm{P}=0.0468$; Table II). No associations were identified between TNFAIP8 or TIPE2 mRNA levels and other clinicopathological characteristics in patients with CRC (all P>0.05; Tables I and II). The levels of TIPE1 and TIPE3 mRNA in tumor tissues exhibited no significant associations with sex, age, tumor site, TNM stage, differentiation degree or lymph node metastasis in patients with CRC (all $\mathrm{P}>0.05$; Tables III and IV).

Linear regression analysis of TIPE family member expression levels in $C R C$. To further investigate the relationships between TIPE family members in CRC, the linear fitting of the relative mRNA levels of TIPE family members with each other in the tumor tissues alone or the paired CRC tumor/adjacent tissues was assessed by linear regression analysis. As presented in Fig. 2A-F, TNFAIP8 expression levels exhibited a positive linear relationship with those of TIPE1 ( $\mathrm{r}=0.5705 ; \mathrm{P}<0.0001)$, TIPE2 ( $\mathrm{r}=0.5967 ; \mathrm{P}<0.0001)$ and TIPE3 ( $\mathrm{r}=0.5359 ; \mathrm{P}<0.0001)$ in the tumor tissues. In addition, a positive linear association was identified between the expression levels of TIPE1 and TIPE2 ( $\mathrm{r}=0.6305 ; \mathrm{P}<0.0001)$, TIPE1 and TIPE3 ( $\mathrm{r}=0.4465$; $\mathrm{P}=0.0013)$, and TIPE2 and TIPE $3(\mathrm{r}=0.3820 ; \mathrm{P}=0.0068)$. The linear regression analysis was also performed on the ratio of the relative mRNA expression of TIPE family members in the tumor tissues to those in the adjacent tissues (T/A). As demonstrated in Fig. 3A-F, the T/A ratio of TNFAIP8 was positively associated with those of TIPE1 $(\mathrm{r}=0.5176 ; \mathrm{P}=0.0001)$, TIPE2 $(\mathrm{r}=0.7156 ; \mathrm{P}<0.0001)$ and TIPE3 $(\mathrm{r}=0.4127 ; \mathrm{P}=0.0032)$. There were also positive linear relationships between the T/A ratio values of TIPE1 and TIPE2 ( $\mathrm{r}=0.6123 ; \mathrm{P}<0.0001)$, TIPE1 and TIPE3 ( $\mathrm{r}=0.6498 ; \mathrm{P}<0.0001$ ), and TIPE2 and TIPE3 ( $\mathrm{r}=0.4441$; $\mathrm{P}=0.0014)$. Therefore, the mRNA levels of the TIPE family members exhibited significant linear relationships with each other.

TIPE family member expression in TCGA CRC data. To further investigate TIPE family expression in CRC, normal colon and colon adenocarcinoma data were obtained from TCGA database. As presented in Fig. 4, the mucinous adenocarcinoma tissues expressed the highest levels of TNFAIP8 and TIPE1, and TNFAIP8 expression levels in the normal tissues were slightly higher compared with those in the adenocarcinoma tissues, 
Table II. Analysis of the association between TIPE2 expression and patient clinicopathological characteristics.

\begin{tabular}{|c|c|c|c|c|c|}
\hline \multirow[b]{2}{*}{ Variable } & \multirow[b]{2}{*}{$\mathrm{n}$} & \multicolumn{2}{|c|}{ TIPE2 expression } & \multirow[b]{2}{*}{$\chi^{2}$} & \multirow[b]{2}{*}{ P-value } \\
\hline & & High, n (\%) & Low, n (\%) & & \\
\hline \multicolumn{6}{|l|}{ Sex } \\
\hline Male & 35 & $21(84.0)$ & $14(58.3)$ & \multirow[t]{2}{*}{3.953} & \multirow[t]{2}{*}{$0.0468^{\mathrm{a}}$} \\
\hline Female & 14 & $4(16.0)$ & $10(41.7)$ & & \\
\hline \multicolumn{6}{|l|}{ Age } \\
\hline$\geq 60$ & 35 & $19(76.0)$ & $16(66.7)$ & \multirow[t]{2}{*}{0.523} & \multirow[t]{2}{*}{0.4697} \\
\hline$<60$ & 14 & $6(24.0)$ & $8(33.3)$ & & \\
\hline \multicolumn{6}{|l|}{ TNM stage } \\
\hline I-II & 30 & $12(48.0)$ & $18(75.0)$ & \multirow[t]{2}{*}{3.760} & \multirow[t]{2}{*}{0.0525} \\
\hline III-IV & 19 & $13(52.0)$ & $6(25.0)$ & & \\
\hline \multicolumn{6}{|c|}{ Lymph node metastasis } \\
\hline Positive & 19 & $13(52.0)$ & $6(25.0)$ & \multirow[t]{2}{*}{3.760} & \multirow[t]{2}{*}{0.0525} \\
\hline Negative & 30 & $12(48.0)$ & $18(75.0)$ & & \\
\hline \multicolumn{6}{|l|}{ Location } \\
\hline Colon & 32 & $17(68.0)$ & $15(62.5)$ & \multirow[t]{2}{*}{0.164} & \multirow[t]{2}{*}{0.6860} \\
\hline Rectum & 17 & $8(32.0)$ & $9(37.5)$ & & \\
\hline \multicolumn{6}{|l|}{ Differentiation grade } \\
\hline Low & 5 & $4(17.4)$ & $1(4.5)$ & \multirow[t]{2}{*}{1.879} & \multirow[t]{2}{*}{0.1705} \\
\hline Medium and high & 40 & $19(82.6)$ & $21(95.5)$ & & \\
\hline
\end{tabular}

${ }^{\mathrm{a}} \mathrm{P}<0.05$. TNM, Tumor-Node-Metastasis; TIPE2, tumor necrosis factor $\alpha$-induced protein 8 -like 2 .

Table III. Analysis of the association between TIPE1 expression and patient clinicopathological characteristics.

\begin{tabular}{|c|c|c|c|c|c|}
\hline \multirow[b]{2}{*}{ Variable } & \multirow[b]{2}{*}{$\mathrm{n}$} & \multicolumn{2}{|c|}{ TIPE1 expression } & \multirow[b]{2}{*}{$\chi^{2}$} & \multirow[b]{2}{*}{ P-value } \\
\hline & & High, $\mathrm{n}(\%)$ & Low, n (\%) & & \\
\hline \multicolumn{6}{|l|}{ Sex } \\
\hline Male & 35 & $20(80.0)$ & $15(62.5)$ & \multirow[t]{2}{*}{1.838} & \multirow[t]{2}{*}{0.1752} \\
\hline Female & 14 & $5(20.0)$ & $9(37.5)$ & & \\
\hline \multicolumn{6}{|l|}{ Age } \\
\hline$\geq 60$ & 35 & $20(80.0)$ & $15(62.5)$ & \multirow[t]{2}{*}{1.838} & \multirow[t]{2}{*}{0.1752} \\
\hline$<60$ & 14 & $5(20.0)$ & $9(37.5)$ & & \\
\hline \multicolumn{6}{|l|}{ TNM stage } \\
\hline I-II & 30 & $16(64.0)$ & $14(58.3)$ & \multirow[t]{2}{*}{0.166} & \multirow[t]{2}{*}{0.864} \\
\hline III-IV & 19 & $9(36.0)$ & $10(41.7)$ & & \\
\hline \multicolumn{6}{|c|}{ Lymph node metastasis } \\
\hline Positive & 30 & $16(64.0)$ & $14(58.3)$ & \multirow[t]{2}{*}{0.166} & \multirow[t]{2}{*}{0.864} \\
\hline Negative & 19 & $9(36.0)$ & $10(41.7)$ & & \\
\hline \multicolumn{6}{|l|}{ Location } \\
\hline Colon & 32 & $16(64.0)$ & $16(66.7)$ & \multirow[t]{2}{*}{0.038} & \multirow[t]{2}{*}{0.8446} \\
\hline Rectum & 17 & $9(36.0)$ & $8(33.3)$ & & \\
\hline \multicolumn{6}{|l|}{ Differentiation grade } \\
\hline Low & 5 & $3(13.0)$ & $2(9.1)$ & \multirow[t]{2}{*}{0.178} & \multirow[t]{2}{*}{0.6732} \\
\hline Medium and high & 40 & $20(87.0)$ & $20(90.9)$ & & \\
\hline
\end{tabular}

TNM, Tumor-Node-Metastasis; TIPE1, tumor necrosis factor $\alpha$-induced protein 8-like 1. 
Table IV. Analysis of the association between TIPE3 expression and patient clinicopathological characteristics.

TIPE3 expression

Variable

$\mathrm{n}$

High, n (\%)

Low, n (\%)

$\chi^{2}$

P-value

Sex

Male

35

$20(80.0)$

$15(62.5)$

1.838

0.1752

Female

14

$5(20.0)$

$9(37.5)$

Age, years

$\geq 60$
$<60$

35
14

$18(72.0)$

$17(70.8)$

0.008

0.9280

TNM stage

I-II 30

$30 \quad 13(52.0)$

7 (29.2)

III-IV

19

$12(48.0)$

$17(70.8)$

1.829

0.1762

Lymph node metastasis

\begin{tabular}{|c|c|c|c|c|c|}
\hline Positive & 19 & $12(48.0)$ & $7(29.2)$ & 1.829 & 0.1762 \\
\hline Negative & 30 & $13(52.0)$ & $17(70.8)$ & & \\
\hline \multicolumn{6}{|l|}{ Location } \\
\hline Colon & 32 & $19(76.0)$ & $13(54.2)$ & 2.576 & 0.1085 \\
\hline Rectum & 17 & $6(24.0)$ & $11(45.8)$ & & \\
\hline \multicolumn{6}{|l|}{ Differentiation grade } \\
\hline Low & 5 & $4(17.4)$ & $1(4.5)$ & 1.879 & 0.1705 \\
\hline Medium and high & 40 & $19(82.6)$ & $21(95.5)$ & & \\
\hline
\end{tabular}

TNM, Tumor-Node-Metastasis; TIPE3, tumor necrosis factor $\alpha$-induced protein 8 -like 3.
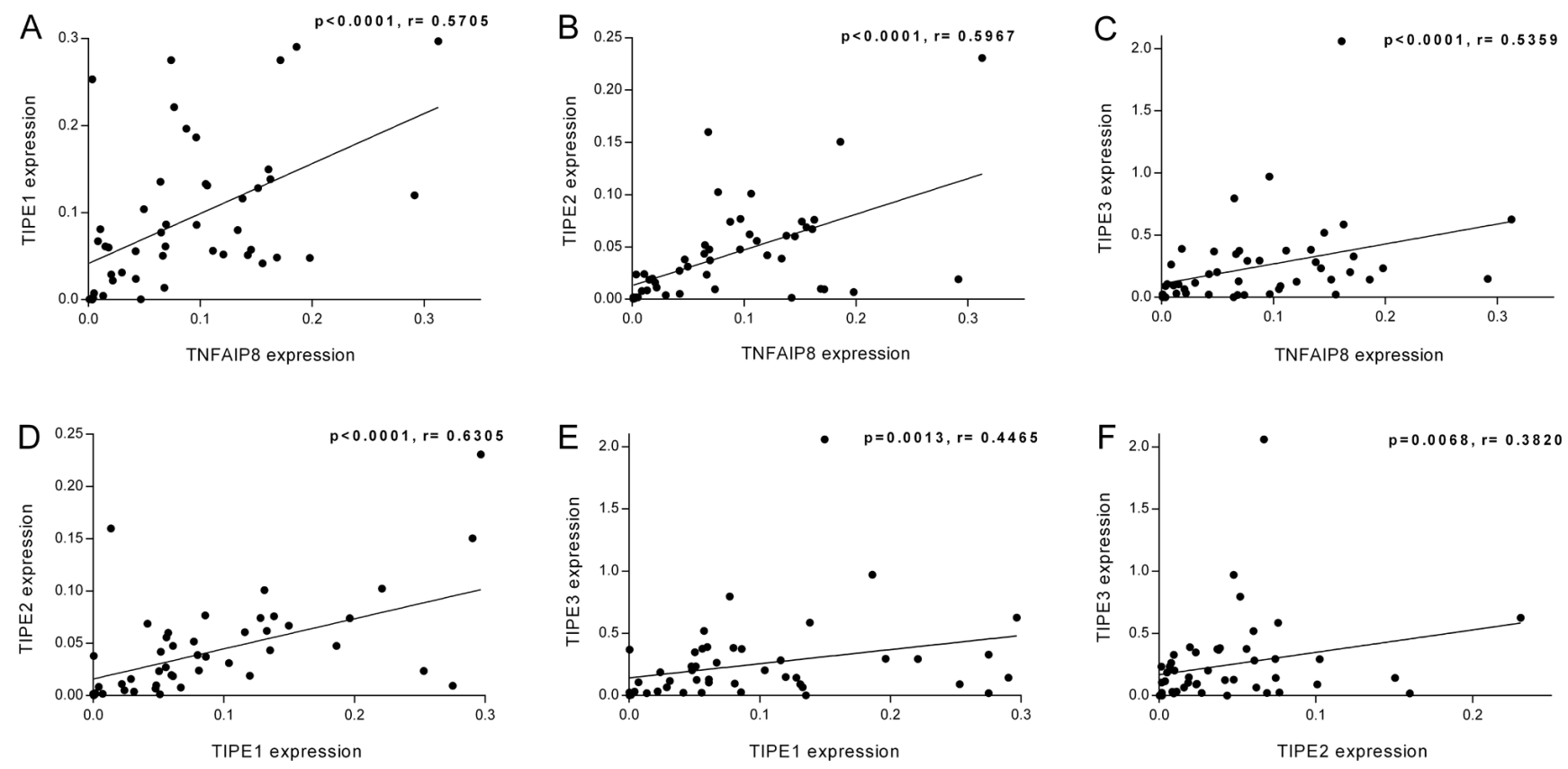

Figure 2. Linear regression analysis of the mRNA expression levels between each pair of TIPE family members in tumor tissues from patients with colorectal cancer. Linear regression between the relative mRNA expression levels of (A) TNFAIP8 and TIPE1, (B) TNFAIP8 and TIPE2, (C) TNFAIP8 and TIPE3, (D) TIPE1 and TIPE2, (E) TIPE1 and TIPE3, and (F) TIPE2 and TIPE3. $n=49$. TNFAIP8, tumor necrosis factor $\alpha$-induced protein 8; TIPE, TNFAIP8-like.

whereas TIPE1 levels were slightly lower in the normal tissues compared with those in the adenocarcinoma tissues (both $\mathrm{P}>0.05$; Fig. 4A and B). The expression levels of TIPE2 and TIPE3 were the highest in the normal colon tissues (Fig. 4C and D). The expression levels of TIPE2 in the mucinous adenocarcinoma tissues were slightly higher compared with those in the adenocarcinoma tissues, whereas the expression levels of TIPE3 in the adenocarcinoma tissues were slightly higher compared with 

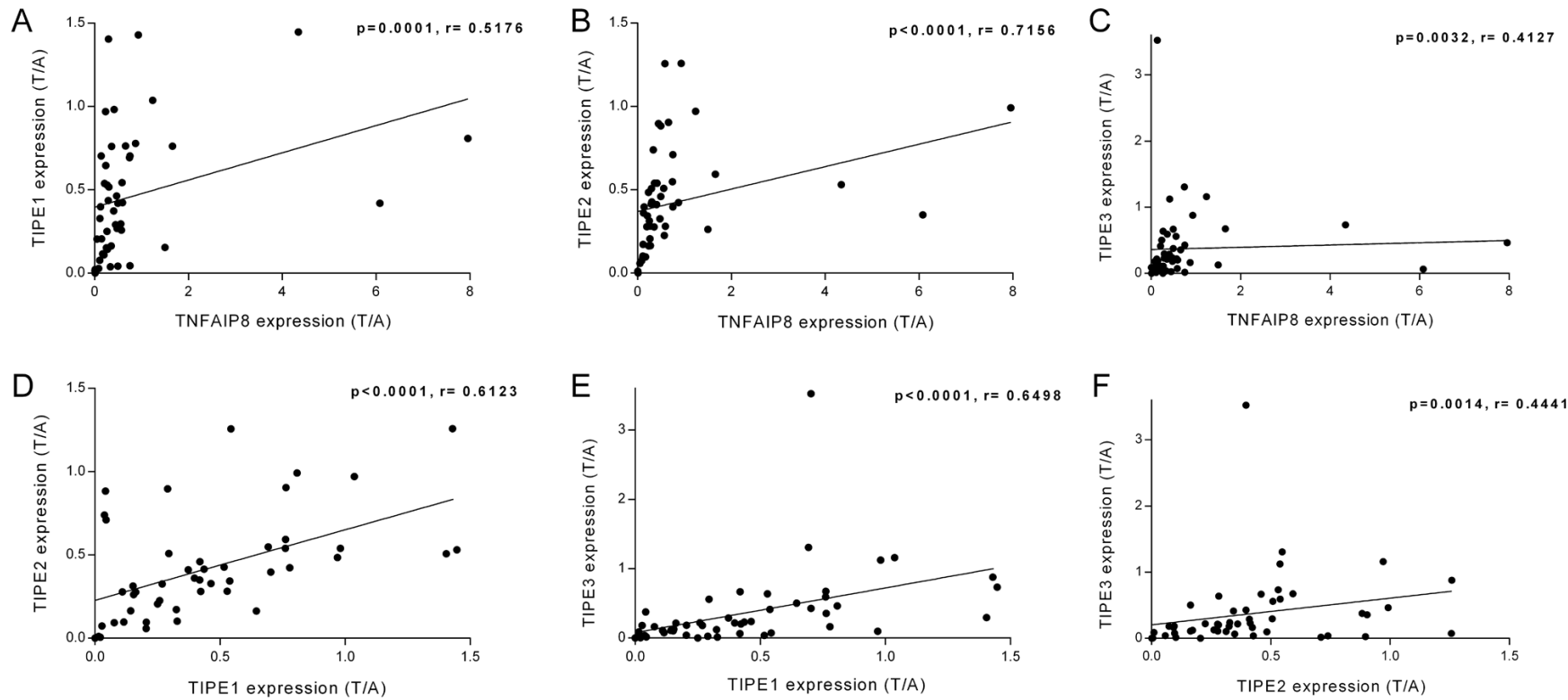

Figure 3. Comparison of the ratio of mRNA expression in the tumor and adjacent tissues from patients with colorectal cancer between TIPE family members. Linear regression between the T/A ratios of (A) TNFAIP8 and TIPE1, (B) TNFAIP8 and TIPE2, (C) TNFAIP8 and TIPE3, (D) TIPE1 and TIPE2, (E) TIPE1 and TIPE3, and (F) TIPE2 and TIPE3. $n=49$. T/A, tumor/adjacent tissue; TNFAIP8, tumor necrosis factor $\alpha$-induced protein 8; TIPE, TNFAIP8-like.

A

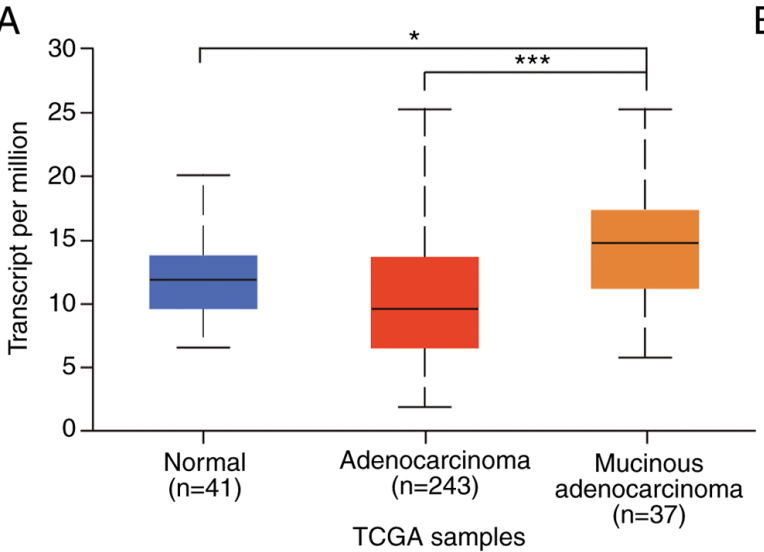

C

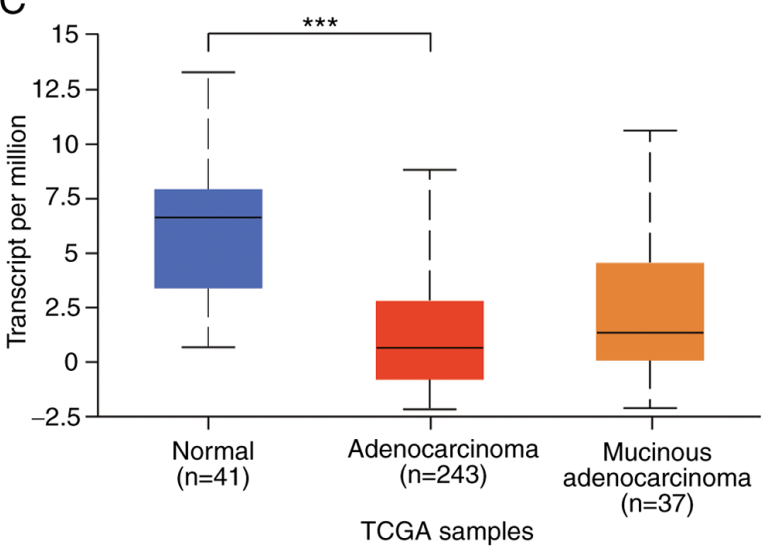

B

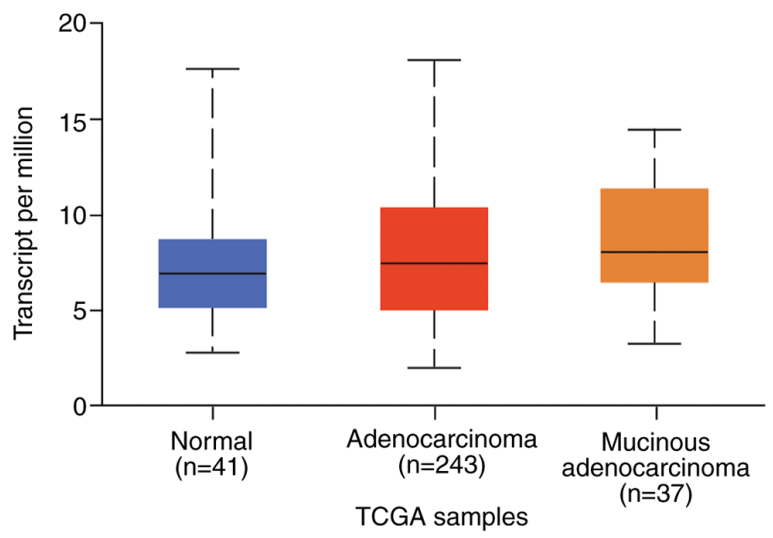

$\mathrm{D}$

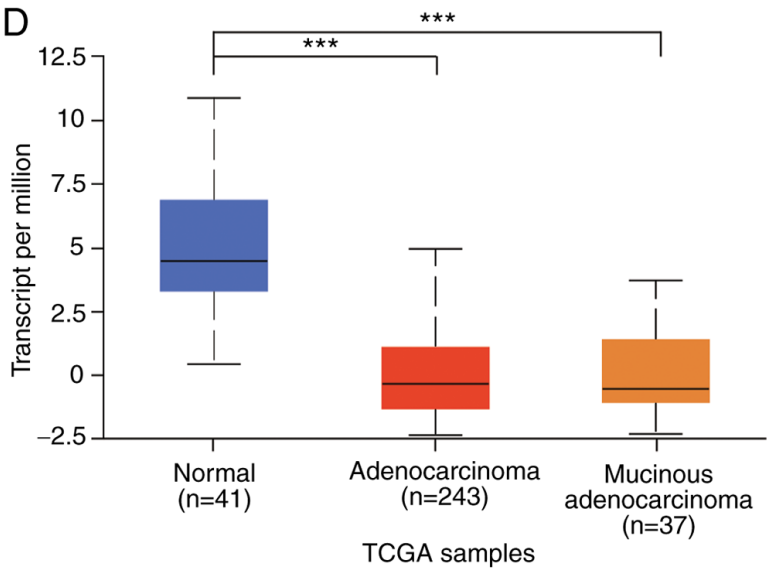

Figure 4. Analysis of TIPE family member mRNA expression in colon adenocarcinoma samples in TCGA dataset. Transcript levels of (A) TNFAIP8, (B) TIPE1, (C) TIPE2 and (D) TIPE3 in patients with adenocarcinoma $(n=243)$, mucinous adenocarcinoma ( $\mathrm{n}=37$ ) and normal colon $(\mathrm{n}=41)$ tissue samples collected in TCGA. ${ }^{*} \mathrm{P}<0.05$ and ${ }^{* * *} \mathrm{P}<0.001$. TNFAIP8, tumor necrosis factor $\alpha$-induced protein 8; TIPE, TNFAIP8-like; TCGA, The Cancer Genome Atlas.

those in the mucinous adenocarcinoma tissues (both $\mathrm{P}>0.05$ ). The results of TCGA data analysis demonstrated that the expression trends of TIPE, TIPE2 and TIPE3 were consistent with the experimental results of the present study, and that their expression levels in the normal colon tissues were higher compared with those in adenocarcinoma. 


\section{Discussion}

The present study evaluated the mRNA expression levels of all TIPE family members in CRC and adjacent tissues. The results demonstrated that the mRNA levels of TNFAIP8, TIPE1, TIPE2 and TIPE3 in the CRC tissues were significantly lower compared with those in the paired adjacent tissues.

Previous studies have demonstrated that the expression of TNFAIP8 protein is upregulated in $\sim 50 \%$ of cancer tissues compared with adjacent non-tumor tissue in patients with $\mathrm{CRC}$ and is associated with the degree of malignancy of the tumor $(34,36)$. However, it is unclear whether TNFAIP8 isoform a functions in cancer and whether the levels of TNFAIP8 v2 mRNA increases alongside those of TNFAIP8 isoform $b$ in CRC tissues. In the present study, the primers used to amplify TNFAIP8 targeted TNFAIP8 $\mathrm{v} 1$ and $\mathrm{v} 3$, which encode isoform a. Notably, the expression pattern of TNFAIP8 mRNA was consistent with that in the previous study by Lowe et al (4). A number of previous studies have confirmed that TNFAIP8 serves a signal transmission role in tumorigenesis. For example, TNFAIP8 promotes the proliferation and invasion of MDA-MB- 435 breast cancer cells by increasing the expression of VEGFR-2, MMP1 and MMP9 (37). TNFAIP8 interacts with large tumor suppressor kinase 1, regulates Hippo signaling in lung and liver cancer cells, and induces cell proliferation, migration and invasion (38). In addition, depletion of TNFAIP8 in HeLa cervical cancer cells activates caspase-3/8, induces p38 phosphorylation and promotes cisplatin-induced apoptosis and cell death (39). As for upstream regulators, the expression level of TNFAIP8 can be upregulated by NF- $\mathrm{KB}$ and TNF- $\alpha$ in diversified cell lines (40). Gao et al, experimentally proved microRNA-9 to negatively regulate the expression of TIPE, and induction of microRNA-9 resulted in reduced TIPE levels and reduced GC cell proliferation in vitro and tumor growth in vivo (41). The results of the present study also demonstrated that in samples from five patients with CRC, the expression levels of TNFAIP8 protein were upregulated in three tumor tissues compared with those in the adjacent tissues. Therefore, the protein level of TNFAIP8 may be affected by the crosstalk of a number of signaling pathways.

Although TCGA data analysis in the present study demonstrated that TIPE1 mRNA levels were not significantly different between the normal colon and CRC tissues, recent studies have stated that TIPE1 is downregulated in CRC compared with adjacent non-tumor tissues, and that TIPE1 overexpression inhibits cell proliferation by suppressing the Wnt/ $\beta$-catenin signaling pathway in CRC $(16,32)$. TIPE1 primers used in the present study targeted both transcript variants. The results of the present study demonstrated that TIPE1 mRNA expression levels were significantly downregulated in the CRC tissues compared with those in the adjacent tissues, and that TIPE1 protein levels were consistent with the mRNA levels in five randomly selected pairs of samples. These results were consistent with previous findings in HCC, gastric and lung cancer $(15,17,18)$. As aforementioned, TIPE1 interacts with Rac1 and inhibits p65 and c-Jun N-terminal kinase in liver cancer cells (15). TIPE1 promotes autophagy by decreasing mTOR phosphorylation in dopaminergic neuronal cells (42). In addition, TIPE1 is required for both zVAD and TNF- $\alpha$-induced necroptosis (43). Therefore, we hypothesize that the downregulation of TIPE1 may lead to decreased cell death and enhanced colorectal tumorigenesis.

As a negative regulator of immunity and inflammation, TIPE2 expression levels are downregulated in most types of cancer tissues compared with those in adjacent normal tissues $(5,20-23)$. However, a previous study has reported higher levels of TIPE2 protein in tissues from patients with CRC compared with those in healthy human colon tissues collected by colonoscopy (35). In contrast to this, the results of the present study demonstrated that TIPE2 mRNA expression levels were downregulated in the CRC tissues compared with those in the paired adjacent tissues, and TIPE2 protein and mRNA expression levels were consistent in five random samples. TCGA data also supported these results. TIPE2 reduces the phosphorylation of protein kinase B/AKT and ERK1/2 and enhances the activation of caspase- 9 and caspase-3 to promote apoptosis in gastric cancer cells (44). In HCC cells, overexpression of TIPE2 decreases the expression levels of MMP-9 and urokinase plasminogen activator by inhibiting the Racl pathway, thus suppressing tumor invasion and metastasis, and abrogates the effects of TNF- $\alpha$-induced cell migration by reducing MMP-13/-3, inhibiting the activation of ERK1/2 and NF- $\kappa \mathrm{B}(45,46)$. On the other hand, a number of inflammatory diseases are associated with downregulated levels of TIPE2 (47-49). Therefore, low expression levels of TIPE2 may attenuate apoptosis and promote invasion and metastasis in CRC.

TIPE3 may function differently in different cancers. A previous study has reported that TIPE3 promotes tumorigenesis by increasing the levels of phosphatidylinositol 4,5-bisphosphate and phosphatidylinositol 3,4,5-trisphosphate in the cell plasma membrane and is expressed at higher levels in lung, esophageal and cervical cancer, as well as colorectal adenocarcinoma tissues compared with the adjacent tissues (27). The results of the present study demonstrated a decrease in TIPE3 mRNA levels ( $\mathrm{v} 1$ and v2) in the CRC samples compared with those in the adjacent tissues, and TIPE3 protein (isoform 1) and mRNA expression patterns were not consistent in five randomly selected pairs of CRC and adjacent tissue samples. Thus, the mRNA and protein expression patterns and functions of TIPE3 in CRC remain to be fully elucidated.

As aforementioned, with the exception of TIPE2, TIPE family members have a range of transcript variants $(4,12,28,30)$. The results of the present study confirmed that the mRNA levels of TIPE2 and the targeted transcript variants of TNFAIP8, TIPE1 and TIPE3 were downregulated in the CRC tissues compared with those in the adjacent tissues. Considering the structural similarity of the TIPE family members, we hypothesize that during the development of CRC, the downregulation of TIPE family member expression levels may be interrelated. In TCGA data analysis results, with the exception of TIPE3, TIPE family member mRNA expression levels were all upregulated in colon mucinous adenocarcinoma compared with those in colon adenocarcinoma, which suggested that the high malignancy histological subtypes of colon cancer may affect the transcription of the TIPE family members. In addition, TNFAIP8 and TIPE3 protein levels were not consistent with their mRNA expression levels, which may be explained by one of the following phenomena: i) Different transcript 
variants may have different contributions to the overall protein levels; ii) posttranscriptional regulation may be involved in the expression of related proteins; and iii) posttranslational regulation, such as delayed protein degradation, may participate in maintaining protein stability, which increases TNFAIP8 and TIPE3 protein levels in CRC.

The results of the present study identified a significant positive linear relationship among the expression levels of TIPE family members and among the T/A ratios of mRNA expression for each pair of genes. TIPE1 and TIPE2 exhibited the highest regression coefficient. For the T/A ratio of mRNA expression, the strongest linear relationship was between the T/A ratios of TNFAIP8 ( $\mathrm{v} 1$ and $\mathrm{v} 3$ ) and TIPE2. The results of TCGA data analysis also revealed that the levels of TNFAIP8, TIPE1 and TIPE2, especially those of TNFAIP8 and TIPE2, were positively associated with each other. As the linear relationship between TIPE2 and the rest members of the TIPE family was statistically significant, whether it is the linear relationship between the tumor or the T/A ratio, it was hypothesized that low TIPE2 expression levels may cause the downregulation of the mRNA levels of the other three TIPE family members and serve a predominant role in CRC tumorigenesis.

A higher degree of tumor differentiation was associated with lower expression levels of TNFAIP8 mRNA. In male patients with CRC, TIPE2 expression levels were significantly higher compared with those in female patients. No significant differences were observed between the expression levels of TIPE family members and other clinicopathological features in the CRC samples. However, the number of samples was limited in the present study, suggesting that additional samples should be collected for further research on the associations between the TIPE family members and patient clinicopathological characteristics. The present study demonstrated that 4 members of the TIPE family are closely related to the tumorigenesis and development of CRC. In addition, these 4 members influenced each other and TIPE2 may serve a significant role in CRC.

\section{Acknowledgements}

The authors would like to thank Mrs. Xiaoli Liu, Miss Jiarong Chen and Dr Guoliang Yan (School of Medicine, Xiamen University, Xiamen, China) for advice on statistical analysis.

\section{Funding}

This study was supported by the Natural Science Foundation of Fujian Province (grant nos. 2015J01530 and 2018J01138), Xiamen Science and Technology Project (grant no. 3502Z20209039), The Joint Research Project of Health and Education of Fujian Province (grant no. WKJ2016-2-17) and XMU Undergraduate Innovation and Entrepreneurship Training Programs (grant no. 201810384226).

\section{Availability of data and materials}

All data generated or analyzed during this study are included in this published article.

\section{Authors' contributions}

YW, SZ and GZ designed the study. MZ, ZC, YY, AB, $\mathrm{XC}, \mathrm{HC}, \mathrm{HR}, \mathrm{KQ}$ and $\mathrm{ZH}$ performed the experiments and analyzed the data. MZ, ZC and YY contributed to the drafting of the manuscript.. All authors read and approved the final manuscript.

\section{Ethics approval and consent to participate}

This study was approved by the Committee on Medical Ethics of Zhongshan Hospital, Xiamen University (Xiamen, China) [approval no. xmzsyyky (2020-137)].

\section{Patient consent for publication}

Not applicable.

\section{Competing interests}

The authors declare that they have no competing interests.

\section{References}

1. Siegel RL, Miller KD, Goding Sauer A, Fedewa SA, Butterly LF, Anderson JC, Cercek A, Smith RA and Jemal A: Colorectal cancer statistics, 2020. CA Cancer J Clin 70: 145-164, 2020.

2. Kuipers EJ, Grady WM, Lieberman D, Seufferlein T, Sung JJ, Boelens PG, van de Velde CJ and Watanabe T: Colorectal cancer. Nat Rev Dis Primers 1: 15065, 2015.

3. Schreuders EH, Ruco A, Rabeneck L, Schoen RE, Sung JJ, Young GP and Kuipers EJ: Colorectal cancer screening: A global overview of existing programmes. Gut 64: 1637-1649, 2015.

4. Lowe JM, Nguyen TA, Grimm SA, Gabor KA, Peddada SD, Li L, Anderson CW, Resnick MA, Menendez D and Fessler MB: The novel p53 target TNFAIP8 variant 2 is increased in cancer and offsets p53-dependent tumor suppression. Cell Death Differ 24: 181-191, 2017.

5. Padmavathi G, Banik K, Monisha J, Bordoloi D, Shabnam B, Arfuso F, Sethi G, Fan L and Kunnumakkara AB: Novel tumor necrosis factor- $\alpha$ induced protein eight (TNFAIP8/TIPE) family: Functions and downstream targets involved in cancer progression. Cancer Lett 432: 260-271, 2018.

6. Bordoloi D, Banik K, Shabnam B, Padmavathi G, Monisha J, Arfuso F, Dharmarajan A, Mao X, Lim LHK, Wang L, et al: TIPE family of proteins and its implications in different chronic diseases. Int J Mol Sci 19: 2974, 2018.

7. Sun H, Gong S, Carmody RJ, Hilliard A, Li L, Sun J, Kong L, $\mathrm{Xu} \mathrm{L}$, Hilliard $\mathrm{B}, \mathrm{Hu} \mathrm{S}$, et al: TIPE2, a negative regulator of innate and adaptive immunity that maintains immune homeostasis. Cell 133: 415-426, 2008

8. Zhang S, Zhang Y, Wei X, Zhen J, Wang Z, Li M, Miao W, Ding H, Du P, Zhang W, et al: Expression and regulation of a novel identified TNFAIP8 family is associated with diabetic nephropathy. Biochim Biophys Acta 1802: 1078-1086, 2010.

9. You Z, Ouyang H, Lopatin D, Polver PJ and Wang CY: Nuclear factor-kappa B-inducible death effector domain-containing protein suppresses tumor necrosis factor-mediated apoptosis by inhibiting caspase-8 activity. J Biol Chem 276: 26398-26404, 2001.

10. Kumar D, Whiteside TL and Kasid U: Identification of a novel tumor necrosis factor-alpha-inducible gene, SCC-S2, containing the consensus sequence of a death effector domain of fas-associated death domain-like interleukin-1beta-converting enzyme-inhibitory protein. J Biol Chem 275: 2973-2978, 2000.

11. Zhang L, Liu R, Luan YY and Yao YM: Tumor necrosis factor- $\alpha$ induced protein 8: Pathophysiology, clinical significance, and regulatory mechanism. Int J Biol Sci 14: 398-405, 2018.

12. Niture S, Dong X, Arthur E, Chimeh U, Niture SS, Zheng W and Kumar D: Oncogenic role of tumor necrosis factor $\alpha$-induced protein 8 (TNFAIP8). Cells 8: 9, 2018. 
13. Laliberte B, Wilson AM, Nafisi H, Mao H, Zhou YY, Daigle M and Albert PR: TNFAIP8: A new effector for Galpha(i) coupling to reduce cell death and induce cell transformation. J Cell Physiol 225: 865-874, 2010.

14. Day TF, Mewani RR, Starr J, Li X, Chakravarty D, Ressom H, Zou X, Eidelman O, Pollard HB, Srivastava M and Kasid UN: Transcriptome and proteome analyses of TNFAIP8 knockdown cancer cells reveal new insights into molecular determinants of cell survival and tumor progression. Methods Mol Biol 1513: 83-100, 2017.

15. Zhang Z, Liang X, Gao L, Ma H, Liu X, Pan Y, Yan W, Shan H, Wang Z, Chen YH and Ma C: TIPE1 induces apoptosis by negatively regulating Rac1 activation in hepatocellular carcinoma cells. Oncogene 34: 2566-2574, 2015

16. Ye T, Yang B, Wang C, Su C, Luo J, Yang X, Yu H, Yuan Z, Meng Z and Xia J: TIPE1 impairs stemness maintenance in colorectal cancer through directly targeting $\beta$-catenin. Carcinogenesis 41 $25-35,2020$.

17. Wu X, Ma Y, Cheng J, Li X, Zheng H, Jiang L and Zhou R TIPE1 function as a prognosis predictor and negative regulator of lung cancer. Oncotarget 8: 78496-78506, 2017.

18. Liu W, Chen Y, Xie H, Guo Y, Ren D, Li Y, Jing X, Li D, Wang X, Zhao M, et al: TIPE1 suppresses invasion and migration through down-regulating Wnt/ $\beta$-catenin pathway in gastric cancer. J Cell Mol Med 22: 1103-1117, 2018.

19. Cui J, Zhang G, Hao C, Wang Y, Lou Y, Zhang W, Wang J and Liu S: The expression of TIPE1 in murine tissues and human cell lines. Mol Immunol 48: 1548-1555, 2011.

20. Shen P, Zhang H, Su Z, Wang S and Xu H: In silico analysis of tumor necrosis factor $\alpha$-induced protein 8-like-1 (TIPE1) protein. PLoS One 10: e0134114, 2015

21. Zhao Q, Zhao M, Dong T, Zhou C, Peng Y, Zhou X, Fan B, Ma W, Han $M$ and Liu S: Tumor necrosis factor- $\alpha$-induced protein- 8 like-2 (TIPE2) upregulates p27 to decrease gastic cancer cel proliferation. J Cell Biochem 116: 1121-1129, 2015.

22. Wang K, Ren Y, Liu Y, Zhang J and He JJ: Tumor necrosis factor (TNF)- $\alpha$-induced protein 8-like-2 (TIPE2) inhibits proliferation and tumorigenesis in breast cancer cells. Oncol Res 25: 55-63, 2017.

23. Li Y, Li X, Liu G, Sun R, Wang L, Wang J and Wang H: Downregulated TIPE2 is associated with poor prognosis and promotes cell proliferation in non-small cell lung cancer. Biochem Biophys Res Commun 457: 43-49, 2015.

24. Gus-Brautbar Y, Johnson D, Zhang L, Sun H, Wang P, Zhang S, Zhang L and Chen YH: The anti-inflammatory TIPE2 is an inhibitor of the oncogenic Ras. Mol Cell 45: 610-618, 2012.

25. Liu MW, Liu R, Wu HY, Zhang W, Xia J, Dong MN, Yu W, Wang Q, Xie FM, Wang R, et al: Protective effect of Xuebijing injection on D-galactosamine- and lipopolysaccharide-induced acute liver injury in rats through the regulation of p38 MAPK, MMP-9 and HO-1 expression by increasing TIPE2 expression. Int J Mol Med 38: 1419-1432, 2016.

26. Zhang H, Zhu T, Liu W, Qu X, Chen Y, Ren P, Wang Z, Wei X, Zhang Y and Yi F: TIPE2 acts as a negative regulator linking NOD2 and inflammatory responses in myocardial ischemia/reperfusion injury. J Mol Med (Berl) 93: 1033-1043, 2015.

27. Fayngerts SA, Wu J, Oxley CL, Liu X, Vourekas A, Cathopoulis T, Wang Z, Cui J, Liu S, Sun H, et al: TIPE3 is the transfer protein of lipid second messengers that promote cancer. Cancer Cell 26 465-478, 2014

28. Yuan F, Liu B, Xu Y, Li Y, Sun Q, Xu P, Geng R, Den G, Yang J, Zhang S, et al: TIPE3 is a regulator of cell apoptosis in glioblastoma. Cancer Lett 446: 1-14, 2019.

29. Wang G, Guo C, Zhao H, Pan Z, Zhu F, Zhang L and Wang Q: TIPE3 differentially modulates proliferation and migration of human non-small-cell lung cancer cells via distinct subcellular location. BMC Cancer 18: 260, 2018.

30. Ren XY, Wen X, Li YQ, Zhang J, He QM, Yang XJ, Tang XR, Wang YQ, Zhang PP, Chen XZ, et al: TIPE3 hypermethylation correlates with worse prognosis and promotes tumor progression in nasopharyngeal carcinoma. J Exp Clin Cancer Res 37: 227, 2018 .

31. Schmittgen TD and Livak KJ: Analyzing real-time PCR data by the comparative C(T) method. Nat Protoc 3: 1101-1108, 2008.
32. Chandrashekar DS, Bashel B, Balasubramanya SAH, Creighton CJ, Ponce-Rodriguez I, Chakravarthi BVSK and Varambally S: UALCAN: A portal for facilitating tumor subgroup gene expression and survival analyses. Neoplasia 19: 649-658, 2017.

33. Brierley JD, Gospodarowicz MK and Wittekind C (eds.): TNM classification of malignant tumours. 8th edition, Wiley-Blackwell, Hoboken, 2016

34. Miao Z, Zhao T, Wang Z, Xu Y, Song Y, Wu J and Xu H: SCC-S2 is overexpressed in colon cancers and regulates cell proliferation. Tumour Biol 33: 2099-2106, 2012.

35. Li XM, Su JR, Yan SP, Cheng ZL, Yang TT and Zhu Q: A novel inflammatory regulator TIPE2 inhibits TLR4-mediated development of colon cancer via caspase-8. Cancer Biomark 14 233-240, 2014

36. Yang C, Xu W, Meng X, Zhou S, Zhang M and Cui D: SCC-S2 facilitates tumor proliferation and invasion via activating Wnt signaling and depressing hippo signaling in colorectal cancer cells and predicts poor prognosis of patients. J Histochem Cytochem 67: 65-75, 2019.

37. Zhang C, Chakravarty D, Sakabe I, Mewani RR, Boudreau HE, Kumar D, Ahmad I and Kasid UN: Role of SCC-S2 in experimental metastasis and modulation of VEGFR-2, MMP-1, and MMP-9 expression. Mol Ther 13: 947-955, 2006.

38. Han Y, Tang Z, Zhao Y, Li Q and Wang E: TNFAIP8 regulates Hippo pathway through interacting with LATS1 to promote cell proliferation and invasion in lung cancer. Mol Carcinog 57: 159-166, 2018.

39. Wu S, Li W, Wu Z, Cheng T, Wang P, Li N, Liang X, Chi M, Zhang S, Ma Y, et al: TNFAIP8 promotes cisplatin resistance in cervical carcinoma cells by inhibiting cellular apoptosis. Oncol Lett 17: 4667-4674, 2019.

40. Lou Y and Liu S: The tipe (tnfaip8) family in inflammation, immunity, and cancer. Mol Immunol 49: 4-7, 2011.

41. Gao HY, Huo FC, Wang HY and Pei DS: MicroRNA-9 inhibits the gastric cancer cell proliferation by targeting TNFAIP8. Cell Prolif 50: e12331, 2017.

42. Ha JY, Kim JS, Kang YH, Bok E, Kim YS and Son JH: Tnfaip8 $11 / \mathrm{Oxi}-\beta$ binds to FBXW5, increasing autophagy through activation of TSC2 in a Parkinson's disease model. J Neurochem 129: $527-538,2014$

43. Hitomi J, Christofferson DE, Ng A, Yao J, Degterev A, Xavier RJ and Yuan J: Identification of a molecular signaling network that regulates a cellular necrotic cell death pathway. Cell 135: $1311-1323,2008$

44. Zhu Y, Tao M, Wu J, Meng Y, Xu C, Tian Y, Zhou X, Xiang J, Zhang $\mathrm{H}$ and Xie Y: Adenovirus-directed expression of TIPE2 suppresses gastric cancer growth via induction of apoptosis and inhibition of AKT and ERK1/2 signaling. Cancer Gene Ther 23 98-106, 2016

45. Zhang YH, Yan HQ, Wang F, Wang YY, Jiang YN, Wang YN and Gao FG: TIPE2 inhibits TNF- $\alpha$-induced hepatocellular carcinoma cell metastasis via Erk1/2 downregulation and NF- $\kappa \mathrm{B}$ activation. Int J Oncol 46: 254-264, 2015.

46. Cao X, Zhang L, Shi Y, Sun Y, Dai S, Guo C, Zhu F, Wang Q, Wang J, Wang X, et al: Human tumor necrosis factor (TNF)-alpha-induced protein 8-like 2 suppresses hepatocellular carcinoma metastasis through inhibiting Racl. Mol Cancer 12: 149,2013

47. Zhang W, Zhang J, Zhao L, Shao J, Cui J, Guo C, Zhu F, Chen YH and Liu S: TIPE2 protein negatively regulates HBV-specific CD8+ T lymphocyte functions in humans. Mol Immunol 64: 204-209, 2015

48. Wang Y, Jiang Y, Zhou J, Song W, Li J, Wang M, Chen J, Xu R, Zhang J, Ma F, et al: Hepatitis C virus promotes hepatocellular carcinogenesis by targeting TIPE2, a new regulator of DNA damage response. Tumour Biol 37: 15265-15274, 2016.

49. Shi G, Zhao JW, Sun XX, Ma JF, Wang P, He FC and Ming L: TIPE2 is negatively correlated with tissue factor and thrombospondin-1 expression in patients with bronchial asthma. Exp Ther Med 15: 3449-3454, 2018.

This work is licensed under a Creative Commons Attribution-NonCommercial-NoDerivatives 4.0 International (CC BY-NC-ND 4.0) License. 